\title{
INHIBITION AND EXCITATION INDUCED BY GLUTAMIC ACID ON CEREBELLAR INTERNEURONS
}

\author{
Chosaburo Yамамото, Hiroyuki Yamashita, and Tadashi Chujo \\ Department of Physiology, University of Kanazawa \\ Medical School, Kanazawa, 920 Japan
}

\begin{abstract}
Thin sections of guinea pig cerebellum were incubated in an artificial medium and responses of neurons in the granular layer to glutamic acid were studied. About half of these neurons were inhibited by glutamate administered electrophoretically (GI cells) and others were excited (GE cells). The GI cells were also inhibited in a medium containing glutamate. Gamma-amino butyric acid inhibited the GI as well as the GE cells. The inhibition in the GI cells induced by glutamate was not susceptible to picrotoxin or strychnine medication, and was not blocked in a $\mathrm{Cl}$-free medium or in a medium containing $\mathrm{Ca}^{2+}$ in low concentrations and $\mathrm{Mg}^{2+}$ in high concentrations. Some GI cells showed high-amplitude spikes which were recordable at distances of tens of micrometer from the cell. These observations indicate that at least some of the GI cells were large Golgi cells and that the inhibition induced by glutamate in the GI cells was not mediated by inhibitory interneurons.
\end{abstract}

It is well known that glutamic acid exerts inhibitory as well as excitatory action on identified neurons in the invertebrate ganglion (KERKUT et al., 1969; OOMURA et al. 1974). Whether a neuron is excited or inhibited by the amino acid is predictable according to the type of the cell determined by its morphological features and location in the ganglion. On the other hand, glutamic acid has been regarded as an exclusively excitatory agent on the neurons of the mammalian brain (CURTIS and Johnston, 1974). Although the inhibitory effect of glutamate on some neurons in the olfactory bulb has been reported (VON BAUMGARTEN et al., 1963), this was explained by the assumption that glutamate primarily excited inhibitory interneurons which, in turn, caused inhibition in the neurons under observation (CURTIS and JOHNSTON, 1974). In in vivo experiments, however, it can not definitely be concluded that the action of an agent administered to a neuron in the brain is direct or through mediation of interneurons. Therefore,

Received for publication February 14, 1977

山本長三郎, 山下浩之, 中条 正 
we have made experiments in vitro on thin brain sections to see if glutamic acid has a direct inhibitory action on the mammalian central neurons. A part of this work has been published elsewhere (Yамамото et al., 1976).

\section{METHODS}

The procedures for preparation of the tissue and for its incubation have been described (ҮАмАмото, 1974b, 1975). In summary: Guinea pigs were stunned and killed by a blow to the back of the neck and thorax. After the occipital bones were prized away with scissors, the cerebellum and underlying medulla were taken from the skull and the vermis of the cerebellum was isolated on a piece of filter paper covered with the standard medium. Tissue blocks of about $1 \mathrm{~mm}$ thickness were obtained from the uvula and nodulus. They were fixed in a small metal dish with Aron-Alpha (alpha-cyanoacrylate monomer) as an adhesive, covered with the chilled medium, and sectioned to a thickness of $80 \mu \mathrm{m}$ with a Vibrotome (Oxford Laboratories, USA). The plane of sectioning was perpendicular to the long axis of the folium. The tissue block was supported with an agar block fixed at a side of the tissue so that the tissue did not tilt during sectioning. Thin sections thus prepared were incubated in the medium at $37^{\circ} \mathrm{C}$ for more than $40 \mathrm{~min}$ and then transferred into the observation chamber (CHUJO et al., 1975) mounted on a microscope stage (Ergaval, Carl Zeiss, Jena). With the aid of the microscope, layers of the cerebellar cortex were readily identified in these sections. The chamber was continuously perfused with the warm standard or modified medium. The composition of the standard medium was (mM): $\mathrm{NaCl}, 124 ; \mathrm{KCl}$, 5; $\mathrm{KH}_{2} \mathrm{PO}_{4}, 1.24 ; \mathrm{MgSO}_{4}, 1.3 ; \mathrm{CaCl}_{2}, 2.4 ; \mathrm{NaHCO}_{3}, 26$ and glucose, 10. The medium was saturated with $95 \% \mathrm{O}_{2}$ and $5 \% \mathrm{CO}_{2}$. For preparation of the $\mathrm{Cl}$-free medium, $\mathrm{Cl}$ ions in the standard medium were replaced with propionate ions.

Single cell discharges were recorded extracellularly with glass microelectrodes filled with $3 \mathrm{M} \mathrm{NaCl}$ with a 2-6 $\mu \mathrm{m}$ tip diameter. Recording pipettes were filled with $1 \mathrm{M} \mathrm{Na-propionate} \mathrm{when} \mathrm{the} \mathrm{Cl}$-free medium was used instead of the standard medium. For electrophoretic administration of amino acids, pipettes filled with $1 \mathrm{M}$ sodium glutamate ( $\mathrm{pH}$ 8.0) or $1 \mathrm{M} \gamma$-aminobutyric acid (GABA, $\mathrm{pH} 3-4)$ with a tip diameter of $1.5 \mu \mathrm{m}$ were used. A retaining current of $25 \mathrm{nA}$ was passed through the pipettes to reduce spontaneous leakage of amino acids. Since the contour of neurons in the granular layer was not clearly visible in the sections used in these experiments, a recording electrode was initially inserted into the granular layer at random and single cell discharges were observed. Thereafter, a pipette containing glutamate or GABA was advanced until the tip of the pipette touched the cut surface of the tissue near the tip of the recording electrode and the effect of amino acids was examined. 


\section{RESULTS}

\section{Excitation and inhibition induced by glutamate}

As a microelectrode was advanced into the granular layer of $80 \mu \mathrm{m}$-thick cerebellar sections, spontaneously discharging neurons were encountered once every one to five insertions. When a pipette filled with glutamate solution was placed adjacent to the tip of the recording electrode and glutamate was administered electrophoretically, the neurons responded either with an increase or a decrease in the firing rate except for a few neurons which were not affected. According to the responses to glutamate, the neurons encountered in the granular layer are classified as glutamate-inhibited (GI) and gutamate-excited (GE) cells. The chance of encountering a GI cell was almost equal to that of encountering a GE cell irrespective of the part of the granular layer from which the potential was recorded. Therefore, the GI and GE cells appear to be distributed throughout the granular layer, from its deepest to the most superficial portion close to the Purkinje cell layer. It is possible, however, that the ratio between the GI and GE cells may be different when sampling is made with electrodes of finer tips than those used in these experiments. As repeatedly observed in Purkinje cells and neurons elsewhere (Chujo et al., 1975; CURTIS and Johnston, 1974), firing of the GE cells increased in rate during administration of glutamate (Fig. 1B), and eventually

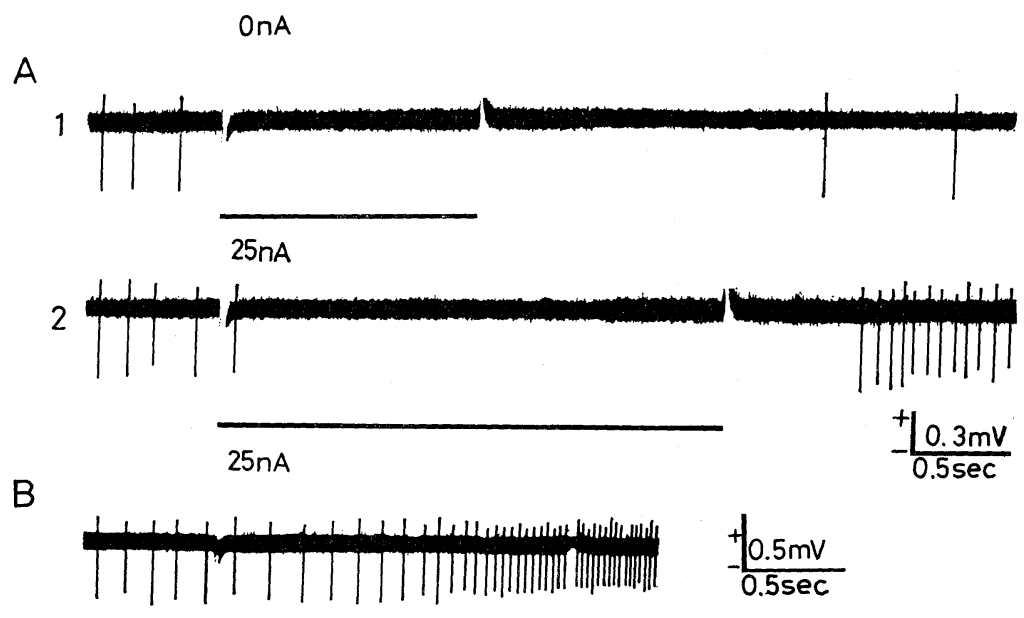

Fig. 1. Responses of neurons in the granular layer to glutamic acid administered iontophoretically. A and B, recorded from a GI and GE cells, respectively. Glutamate was administered during the periods indicated by the solid lines beneath the records. Intensities of the currents are shown above the records. Spikes were retouched in this and in the following illustrations.

stopped due to cathodal block if administration was further continued. In contrast to this, firing of the GI cells gradually decreased in rate and then ceased 


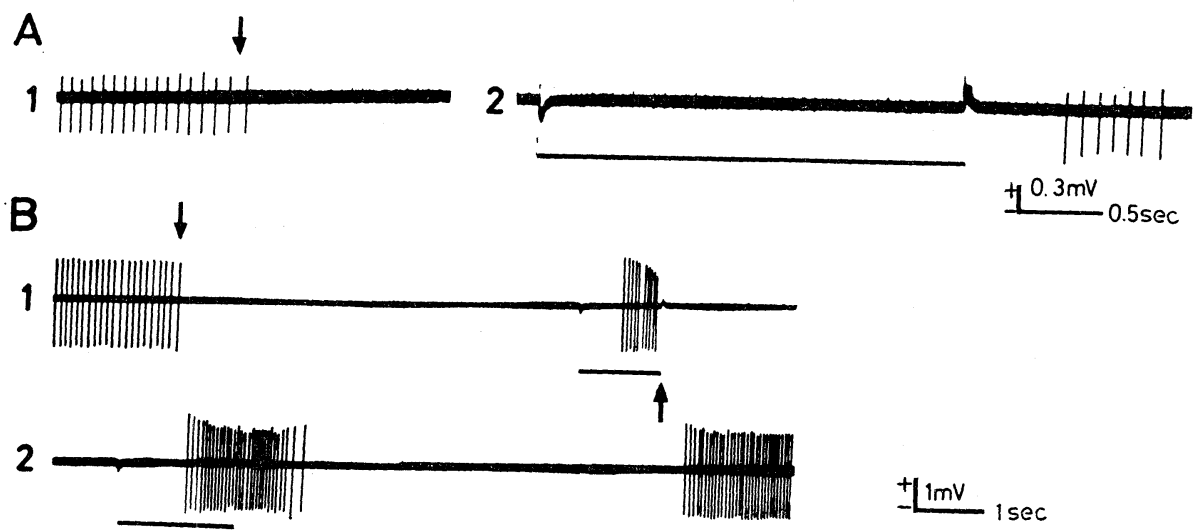

Fig. 2. Generation of spike bursts in GI cells during prolonged administration of glutamate. Downward and upward arrows indicate respectively approximate instances at which a glutamate pipette touched and was withdrawn from the tissue. In A, spontaneous firing ceased when a glutamate pipette was brought into contact with the tissue (record 1). After $28 \mathrm{sec}$, a spike burst was generated following glutamate was ejected with a current of $10 \mathrm{nA}$ for $2.5 \mathrm{sec}$ (record 2, solid line). B, recorded from an exceptional cell. Spontaneous firing stopped while a glutamate pipette was in contact with the tissue, but spike trains were induced during interruption of the retaining current (solid lines). The interval between records 1 and 2 was $30 \mathrm{sec}$.

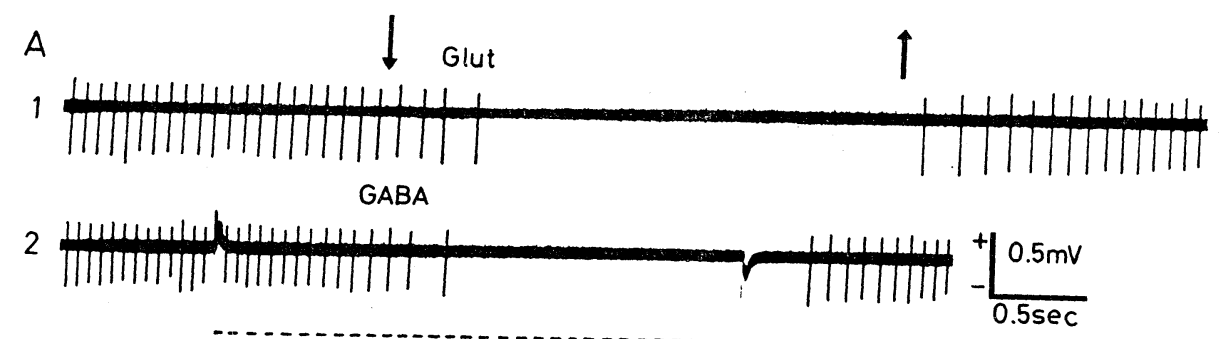

B

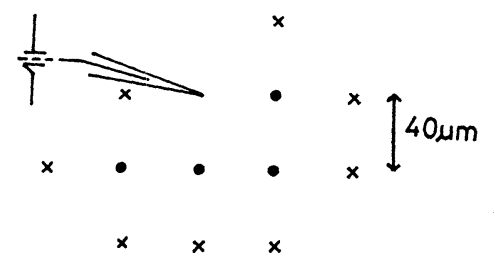

Fig. 3. Glutamate- and GABA-sensitive areas of a GI cell. A-1, a glutamate pipette touched a point indicated by dots in B (downward arrow) and withdrawn (upward arrow). The retaining current was continuously applied. Glut, glutamate. A-2, GABA was administered to the same point with a current of $10 \mathrm{nA}$ (broken line). B, glutamate and GABA suppressed the spontaneous discharges of the cell when administered to the points indicated by dots, but were without effect when administered to the points indicated by crosses. 


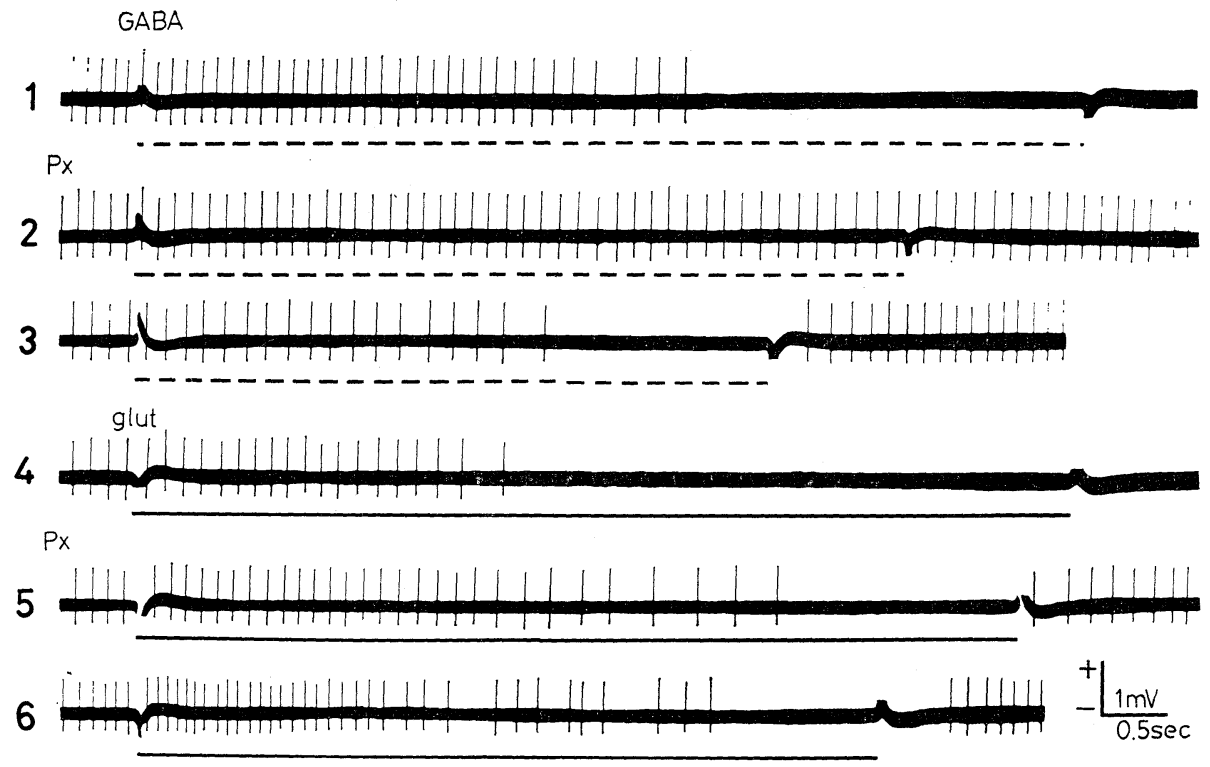

Fig. 4. Effects of picrotoxin. 1, GABA was administered to a cell with a current of $25 \mathrm{nA}$ (broken line) in the standard medium. 2, 5 min after the tissue was perfused with a medium containing picrotoxin $(\mathrm{Px})(65 \mathrm{mg} / \mathrm{liter}) .3,46 \mathrm{~min}$ after the tissue was washed. 4 , glutamate (glut) was administered to the same cell with a current of $25 \mathrm{nA}$ (solid line) in the standard medium. 5, $5 \mathrm{~min}$ after picrotoxin $(65 \mathrm{mg} / \mathrm{liter}) .6,25 \mathrm{~min}$ after washing.
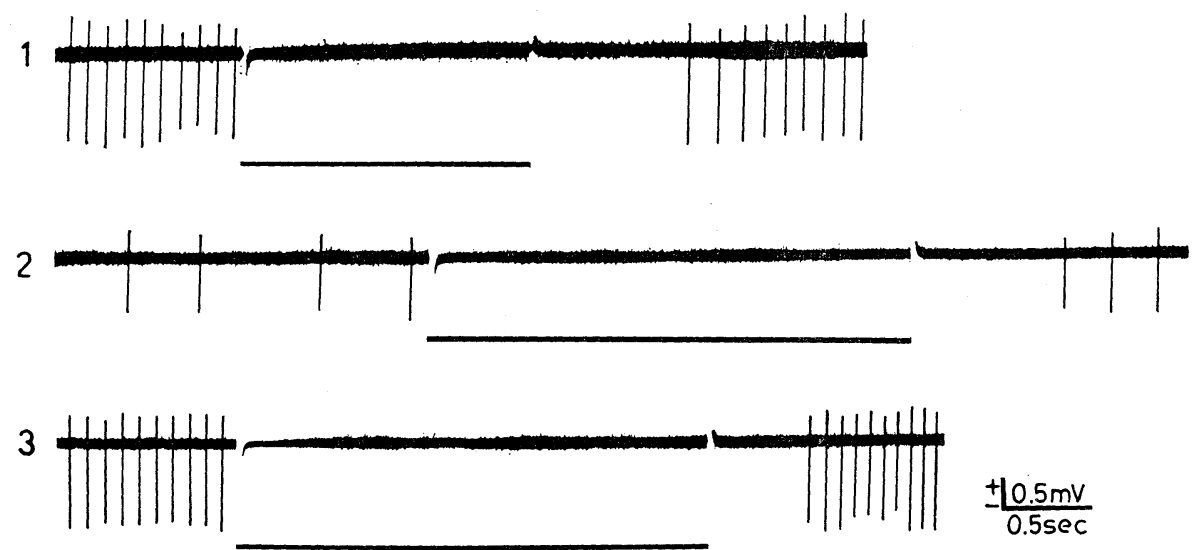

Fig. 5. Concentrations of divalent cations and glutamate inhibition. 1, suppression of firing in the standard medium with glutamate current of $10 \mathrm{nA}$ (solid line). 2, $24 \mathrm{~min}$ after the section was perfused with the medium containing $\mathrm{Ca}^{2+}$ in $0.8 \mathrm{~mm}$ and $\mathrm{Mg}^{2+}$ in $16 \mathrm{~mm}$. 3, 6 min after the section was returned in the standard medium. 
(Fig. 4-4) or, in sensitive cells, it stopped as soon as the electrophoretic current was turned on (Fig. 5). The intensity of the current necessary to cause a complete cessation of firing varied from cell to cell. In the cell illustrated in Fig. 1A, an interruption of the retaining current alone could induce immediate cessation of spontaneous discharges. Occasionally, approach to or touching a glutamatefilled pipette to the surface of the tissue near the recording site caused a complete suppression of firing even though the retaining current was continuously passed through the pipette (Figs. 2 and 3). The possibility may be excluded that this inhibition was induced electrotonically by the retaining current, since approach of a glutamate-filled pipette to these GI cells suppressed firing even though the retaining current was not passed through the pipette. It had previously been reported that occasionally the retaining current could not completely block the background leakage of glutamate (CHujo et al., 1975). Therefore, the inhibition in Figs. 2 and 3 may be attributed to a small amount of glutamate leaking from the tip of the pipette in spite of the retaining current.

After termination of glutamate administration, the inhibition induced by glutamate in the GI cell was sustained usually for 0.5 to several seconds. Sometimes, however, the inhibition was followed by a marked increase in discharge rate that lasted for several seconds, especially when an electrophoretic current of high intensity was used. In the GI cell illustrated in Fig. 1A, for example, spontaneous firing did not occur for $1.5 \mathrm{sec}$ and gradually recovered to the control level after the retaining current was simply interrupted for $1.3 \mathrm{sec}$ and reapplied (record 1). But, the inhibition was followed by discharges at a frequency about three times the control after glutamate was ejected with a current of $25 \mathrm{nA}$ for $2.5 \mathrm{sec}$ (record 2). This phenomenon is called "after-facilitation" in this report.

During a prolonged administration of glutamate, a short burst of spikes was usually induced after the intensity of the current was increased for a short period and then brought back to the previous intensity. In Fig. $2 \mathrm{~A}$, spontaneous firing was continuously suppressed while the tip of a glutamate-filled pipette was in contact with the cut surface of the tissue (record A1, after arrow). Twenty-eight seconds after cessation of firing, glutamate was released deliberately with a current of $10 \mathrm{nA}$ for $2.5 \mathrm{sec}$ (record A2, underlined). Whereas no discharges were initiated during the glutamate current, a short train of spikes occurred with a latency of $0.5 \mathrm{sec}$ after the termination of the current. Thereafter, the cell again remained silent as long as the glutamate pipette was touching the tissue. Exceptionally, the cells illustrated in Fig. 2B were found. While a glutamate-filled pipette was in contact with the tissue, spontaneous firing of these cells was continuously suppressed even if the retaining current was applied (record 1, arrow pointing downwards). When the current was interrupted during this prolonged suppression and amount of leaking glutamate was increased for $1 \mathrm{sec}$, the cell started to fire during the interruption of the current (record 1, underlined). The second interruption of the current for $1.5 \mathrm{sec}$ induced a burst of spikes which 
outlasted the interruption of the current (record 2, underlined). When the glutamate pipette was withdrawn, an after-facilitation occurred and lasted for about $10 \mathrm{sec}$ (record 2, arrow pointing upwards).

In some experiments, neurons encountered in the granular layer were identified as GE or GI cells by means of electrophoretic administration of glutamate, and subsequently the surrounding medium containing glutamate in various concentrations $(0.05-3 \mathrm{~mm})$ was perfused into the chamber. All of six neurons identified as GI cells decreased in firing rate during perfusion with the medium containing glutamate and finally stopped firing within $5 \mathrm{~min}$. Five other neurons identified as GE cells, on the other hand, increased firing rate during perfusion with the medium containing glutamate. When the GI cells with a marked after-facilitation were exposed to media containing glutamate of low concentrations (less than $0.1 \mathrm{~mm}$ ), firing was initially strongly suppressed. As perfusion with the medium containing glutamate was continued, however, the inhibition tended to decline and firing frequency increased gradually, though it did not exceed the frequency observed before administration of glutamate. When the tissue was placed in the medium containing glutamate at higher concentrations, firing was also initially inhibited, but excitation took place within 2-3 min. The excitation had no tendency to decline during prolonged perfusion with the medium containing glutamate.

\section{Glutamate- and GABA-sensitive areas of the GI cells}

Firing of GI cells was suppressed not only by glutamate but also by GABA. In the experiments illustrated in Fig. 3, GABA was administered to points surrounding the site of recording, and the extension of the area was determined in which GABA administration caused inhibition (GABA-sensitive area). The GABA electrode was then replaced with a glutamate pipette, and sites were determined in which administration of glutamate inhibited the same cell (glutamatesensitive area). The electrophoretic current used was slightly higher than that to induce a definite inhibition in the cell when administered adjacent to the tip of the recording electrode. The glutamate-sensitive area of the neuron depicted in Fig. 3 was relatively wide as shown by dots in B and almost coincided with the GABAsensitive area. In some of other five GI cells examined likewise, the glutamatesensitive area was not so wide, but the coincidence between the glutamate- and GABA-sensitive areas was always observed.

The extension of the glutamate-sensitive area was probably determined by distribution of dendritic branches (CHUJO et al., 1975) and the distance of spread of glutamate released from a glutamate pipette. In Fig. 3, spread of glutamate leaking from the pipette tip seems to be restricted because the retaining current was continuously applied (CHUjo et al., 1975). Therefore, the wide glutamatesensitive area in Fig. 3 suggests that some of the GI cells are large neurons which gave a wide distribution of the dendrites. This conjecture may be supported by 
the observation that the spike amplitude of some GI cells exceeded several millivolts though recorded with electrodes of relatively large tips. When biphasic spikes of large amplitude were recorded from the GI cells, the recording electrode was occasionally withdrawn in steps of $10 \mu \mathrm{m}$. Even at distances of tens of micrometer from the cell, spikes were still detectable though they changed to small monophasic spikes of negative polarity. This also suggests that some of the GI cells were large neurons whose action current spread widely around the cell.

\section{Glutamate inhibition in modified media}

In the experiments to be described in this section, studies on whether or not glutamate inhibited the GI cells directly or via intervention of inhibitory interneurons were carried out. In Fig. 4, the actions of glutamate and GABA are compared in the presence of picrotoxin. After it was observed that a GI cell stopped firing during administration of GABA with a current of $25 \mathrm{nA}$ in the standard medium (record 1), the tissue was perfused with the medium containing picrotoxin at a concentration of $65 \mathrm{mg} /$ liter for $5 \mathrm{~min}$. GABA administered subsequently with the same current was found to be no longer effective (record 2). After thorough washing of the tissue with the standard medium, the same cell became again susceptible to GABA (record 3). Thereafter, the inhibition by glutamate was similarly examined in the same cell. Even though the tissue was maintained in a medium containing picrotoxin at the same concentration as before, glutamate was still effective in suppressing the cell (record 5). In different GI cells, the concentration of picrotoxin necessary to block the inhibitory action of GABA ranged from 5 to $80 \mathrm{mg} /$ liter. At the same concentration range of picrotoxin, the inhibition by glutamate was always elicitable. Strychnine also had no effect on the inhibitory effect of glutamate at a concentration of $0.5 \mathrm{mg} / \mathrm{liter}$. The inhibition by GABA was blocked when the tissues were kept for more than 5 min in the medium in which $\mathrm{Cl}^{-}$was replaced by propionate ions. In contrast, the inhibitory action of glutamate was not affected in the $\mathrm{Cl}$-free medium.

Figure 5 shows the effects of changes in the concentration of divalent ions. After a control record was taken in the standard medium (record 1), $\mathrm{Ca}^{2+}$ concentration in the perfusing medium was reduced from 2.4 to $0.8 \mathrm{~mm}$ and $\mathrm{Mg}^{2+}$ concentration was increased from 1.3 to $16 \mathrm{~mm}$. Whereas the spike height and firing frequency decreased in this medium as usually observed, glutamate was still able to inhibit the GI cells (record 2). Not only the inhibition by glutamate but also the after-facilitation was induced in the medium containing $\mathrm{Ca}^{2+}$ in 0.8 and $\mathrm{Mg}^{2+}$ in $16 \mathrm{~mm}$.

\section{DISCUSSION}

As previously reported, all Purkinje cells tested with glutamate were excited in vitro in thin cerebellar sections (CHUJO et al., 1975). This is in contrast with the 
present observation that about half of neurons in the granular layer were inhibited by glutamate. The inhibition does not seem to be induced electrotonically by the electrophoretic current itself because the inhibition was elicited by merely interrupting the retaining current and because the GI cells were consistently inhibited in the medium containing glutamate.

While the inhibition induced in the GI cells by GABA was abolished by picrotoxin and in the $\mathrm{Cl}$-free medium, the inhibition by glutamate was unaffected. Therefore, the glutamate inhibition is not the result of an increased permeability of neuronal membrane to $\mathrm{Cl}^{-}$. The above observations further mean that the inhibition by glutamate was not mediated by interneurons releasing GABA (CURTIS and JOHNSTON, 1974). The intervention of interneurons releasing glycine may be denied by the finding that the inhibition by glutamate was not susceptible to strychnine (CuRTIS and JoHNSTON, 1974). Further, intervention of inhibitory interneurons in the glutamate inhibition seems improbable in view of the results of experiments in which the extension of glutamate- and GABA-sensitive areas were compared. If GABA inhibits the GI cells directly and glutamate, via mediation of interneurons, it would be expected that the GABA- and glutamate-sensitive areas would not coincide with each other. In all the cells examined, however, the coincidence of these two areas was consistent. Moreover, the inhibitory action of glutamate was not abolished when the tissue was placed in a medium containing $\mathrm{Ca}^{2+}$ in low and $\mathrm{Mg}^{2+}$ in high concentrations. It is known that synaptic transmissions in thin brain sections are blocked in such media (RICHARDS and Sercombe, 1970; Yамамото, 1974a). Therefore, it appears impossible that interneurons mediate the glutamate inhibition described in this report.

Firing of some GI cells increased in rate above the control level after the termination of the electrophoretic current for glutamate (after-facilitation). It seems possible that glutamate inhibited the GI cell on the one hand and activated near-by excitatory interneurons on the other which in turn excited the GI cell under the observation. This possibility, however, may be excluded because the afterfacilitation was elicited in the medium containing $\mathrm{Ca}^{2+}$ in low concentrations and $\mathrm{Mg}^{2+}$ in high concentrations. Since neuronal firing takes place generally following hyperpolarization (KANDEL and SPENCER, 1961), the after-facilitation consisting of a short spike burst may be explained by the rebound firing after a hyperpolarization. Occasionally, however, the after-facilitation was too intense and too long-lasting to be explained by a rebound phenomenon. When glutamate was added in the medium, inhibition took place in these GI cells. The inhibition, however, gradually declined at low glutamate concentrations or changed to excitation at higher concentrations. These observations may be explained by the assumption that the GI cells with the after-facilitation have both excitatory and inhibitory receptors for glutamate. The latter is activated at low glutamate concentrations with short latencies but its sensitivity decreases during prolonged exposure to glutamate, whereas the former is activated at higher concentrations 
and only after a long administration. This assumption can explain the observation in a few exceptional GI cells, in which spontaneous discharges were suppressed during contact of a glutamate pipette with the tissue but firing was induced with interruption of the retaining current. Before interruption of the retaining current, leakage of glutamate from the pipette was restricted and neuronal firing was suppressed by activation of the inhibitory receptors alone. When the retaining current was turned off, amount of leaking glutamate increased, so that the excitatory receptors were activated. The excitation was probably strengthened by lowered sensitivity of the inhibitory receptors which occurred during long contact of the pipette with the tissue. WACHTEL and KANDEL (1971) already reported that excitation induced by acetylcholine in an identified neuron of Aplysia was converted to inhibition during repeated administration. They postulated presence of excitatory and inhibitory receptors for acetylcholine in the neuron, the excitatory one being more sensitive to acetylcholine and susceptible to desensitization.

This study was supported by a Scientific Research Grant (B 1976) from the Ministry of Education, Science and Culture of Japan.

\section{REFERENCES}

Chujo, T., Yamada, Y., and Yamamoto, C. (1975) Sensitivity of Purkinje cell dendrites to glutamic acid. Exp. Brain Res., 23: 293-300.

Curtis, D. R. and Johnston, G. A. R. (1974) Amino acid transmitters in the mammalian central nervous system. Ergeb. Physiol., 69: 97-188.

KANDEL, E. R. and SPENCER, W. A. (1961) Electrophysiology of hippocampal neurons. II. After-potentials and repetitive firing. J. Neurophysiol., 24: 243-259.

Kerkut, F. A., Horn, N., and WAlKer, R. J. (1969) Long-lasting synaptic inhibition and its transmitter in the snail Helix aspersa. Comp. Biochem. Physiol., 30: 1061-1074.

Oomura, Y., Ooyama, H., and SAwadA, M. (1974) Analysis of hyperpolarizations induced by glutamate and acetylcholine on Onchidium neurones. J. Physiol. (London), 243: 321-341.

RichaRdS, C. D. and Sercombe, R. (1970) Calcium, magnesium and the electrical activity of guinea-pig olfactory cortex in vitro. J. Physiol. (London), 211: 571-584.

von Baumgarten, R., Bloom, F. E., Oliver, A. P., and Salmoiraghi, G. C. (1963) Response of individual olfactory nerve cells to microelectrophoretically administered chemical substances. Pflügers Arch., 277: 125-140.

WACHTEL, H. and KANDEL, E. R. (1971) Conversion of synaptic excitation to inhibition at a dual chemical synapse. J. Neurophysiol., 34: 56-68.

YамАмото, С. (1974a) Electrical activity recorded from thin sections of the lateral geniculate body, and the effects of 5-hydroxytryptamine. Exp. Brain Res., 19: 271-281.

YАмАмото, С. (1974b) Electrical activity observed in vitro in thin sections from guinea-pig cerebellum. Jap. J. Physiol., 24: 177-188.

ҮАмАмото, С. (1975) Recording of electrical activity from microscopically identified neurons of the mammalian brain. Experientia, 31: 309-311.

Yамамото, C., Yamashita, H., and Chujo, T. (1976) Inhibitory action of glutamic acid on cerebellar interneurones. Nature, 262: 786-787. 